\title{
Hemorrhagic Aspects of Gaucher Disease
}

\author{
Hanna Rosenbaum, M.D. ${ }^{1,2 *}$ \\ ${ }^{\prime}$ Department of Hematology and Bone Marrow Transplantation, Rambam Health Care Campus, Haifa, \\ Israel; and ${ }^{2}$ Bruce Rappaport Faculty of Medicine, Technion-Israel Institute of Technology, Haifa, Israel
}

\begin{abstract}
Gaucher disease (GD) is an inherited lysosomal disorder, originating from deficient activity of the lysosomal enzyme glucocerebrosidase (GCase). Normally, GCase hydrolyzes glucocerebroside (GC) to glucose and ceramide; however, impaired activity of this enzyme leads to the accumulation of GC in macrophages, termed "Gaucher cells." Gaucher disease is associated with hepatosplenomegaly, cytopenias, skeletal complications and in some forms involves the central nervous system.

Coagulation abnormalities are common among GD patients due to impaired production and chronic consumption of coagulation factors. Bleeding phenomena are variable (as are other symptoms of GD) and include mucosal and surgical hemorrhages.

Four main etiological factors account for the hemostatic defect in GD: thrombocytopenia, abnormal platelet function, reduced production of coagulation factors, and activation of fibrinolysis. Thrombocytopenia relates not only to hypersplenism and decreased megakaryopoiesis by the infiltrated bone marrow but also to immune thrombocytopenia. Autoimmunity, especially the induction of platelet antibody production, might cause persistent thrombocytopenia.
\end{abstract}

Enzyme replacement therapy reverses only part of the impaired coagulation system in Gaucher disease. Other therapeutic and supportive measures should be considered to prevent and/or treat bleeding in GD.

\begin{abstract}
Abbreviations: DIC, disseminated intravascular coagulation; ERT, enzyme replacement therapy; FII, factor II; FIX, factor IX; FV, factor V; FVII, factor VII; FX, factor X; FXI, factor XI; GC, glucocerebroside; GD, Gaucher disease; GD1, type 1 Gaucher disease; ITP, immune thrombocytopenia.
\end{abstract}

Citation: Rosenbaum H. Hemorrhagic Aspects of Gaucher Disease. Rambam Maimonides Med J 2014;5 (4):eoo39. doi:10.5041/RMMJ.10173

Copyright: (C) 2014 Rosenbaum. This is an open-access article. All its content, except where otherwise noted, is distributed under the terms of the Creative Commons Attribution License (http://creativecommons.org/licenses/by/3.0), which permits unrestricted use, distribution, and reproduction in any medium, provided the original work is properly cited.

Conflict of interest: No potential conflict of interest relevant to this article was reported.

*E-mail: h_rosenbaum@rambam.health.gov.il 
Gaucher patients should be evaluated routinely for coagulation abnormalities especially prior to surgery and dental and obstetric procedures.

KEY WORDS: Enzyme replacement therapy, Gaucher disease, glucocerebroside, hemostatic abnormalities

\section{INTRODUCTION}

Gaucher disease (GD) is an autosomal recessive inherited disorder of glycolipid storage, caused by a deficiency of the lysosomal enzyme glucocerebrosidase (GCase), which hydrolyzes glucocerebroside (GC) to glucose and ceramide, leading to the accumulation of GC in macrophages and resulting in multiorgan involvement. ${ }^{1}$ The macrophages of mononuclear origin with GC-laden lysosomes (named "Gaucher cells") infiltrate the reticuloendothelial system and involve the liver, spleen, lung, and bone marrow, causing hepatosplenomegaly, anemia, thrombocytopenia, bone disease, and occasionally neurological involvement. ${ }^{2-4}$ Three GD types are characterized by the absence (type 1) or presence of neurologic involvement during childhood (type 2) or adolescence (type 3). ${ }^{1}$

Type 1 Gaucher disease (GD1) is panethnic but particularly common among the Ashkenazi Jewish population. 5 Gaucher disease type 1 may present with a wide range of clinical manifestations, including various hemostatic abnormalities.

Enzyme replacement therapy (ERT) for GD1 has been available since 1991, first as human placentaderived enzyme (alglucerase, Ceredase ${ }^{\circledR}$, Genzyme, a Sanofi Company, Cambridge, MA, USA) and since 1994 as imiglucerase (Cerezyme ${ }^{\circledR}$, Genzyme), a human recombinant form of the enzyme. A second recombinant human enzyme replacement therapy, velaglucerase-alfa (VPRIV) (Shire Human Genetic Therapies, Dublin, Ireland $)^{6,7}$ was approved in 2010, and a third, taliglucerase-alfa (Elelyso ${ }^{\mathrm{TM}}$, Protalix, Carmiel, Israel) which is a plant cell-expressed acid $\beta$-glucocerebrosidase, was approved in the United States and other countries in 2012.8,9

Enzyme replacement therapy is beneficial for most hematological manifestations and some aspects of bone disease in GD patients. ${ }^{10,11}$ Enzyme replacement therapy reduces spleen and liver volumes, reverses or ameliorates the cytopenias following 12-24 months of treatment, and is considered the gold standard treatment for Gaucher type 1 and type 3 patients. ${ }^{12}$
While the hallmark of GD1 is organomegaly due to recurrent infarction, fibrosis, and extramedullary hematopoiesis, hemorrhagic phenomena are frequent, being the presenting symptom in $43 \%$ of Gaucher patients. ${ }^{13}$

The main hemorrhagic manifestations in GD patients are mucosal, including nose, gingiva, heavy menstrual bleeding, and hemorrhages induced by minor trauma, surgery, or labor. ${ }^{14,15}$ Spontaneous iliopsoas hematomas were reported in six GD patients as unusual severe bleeding events. ${ }^{16-19}$

Various coagulation defects contribute to hemorrhagic diathesis in GD, including thrombocytopenia, thrombocytopathy, clotting factor deficiencies, and enhanced fibrinolysis (Table 1).

\section{THROMBOCYTOPENIA}

Bleeding complications in GD are frequently attributed to thrombocytopenia, which commonly occurs due to hypersplenism and/or bone marrow infiltration by Gaucher cells, compromising megakaryopoiesis. Stein et al. reported the presence of focal splenic lesions in GD patients, which was shown to be associated with greater degrees of thrombocytopenia, and lower response of thrombocytopenia to enzyme therapy. ${ }^{20}$

Gaucher disease appears to be associated with an increased incidence of immunological disorders, such as immune thrombocytopenia (ITP). ${ }^{21,22}$ The controversial issue of platelet-associated antibodies in the diagnosis of ITP in GD patients was previously presented in a case report and in an abstract form. Further studies are warranted to assess the role of platelet-associated antibodies in ITP observed in GD patients.

Hemorrhagic complications appear to be mainly related to the severity of thrombocytopenia. Others believe that platelet count alone may not be a reliable indicator of bleeding risk in GD patients. ${ }^{23} \mathrm{~A}$ higher risk of bleeding during (orthopedic) surgery is considered with a platelet count below 20x 109/L. ${ }^{24}$ Thrombocytopenia frequently normalizes within 1 to 2 years of ERT in patients with an intact 
Table 1. Hemostatic Abnormalities in Gaucher Disease: Evaluation and Therapeutic Approach.

\begin{tabular}{|c|c|c|}
\hline & Diagnostic Methods & Therapeutic Approach \\
\hline \multirow[t]{5}{*}{ Thrombocytopenia } & Complete blood count & Enzyme replacement therapy (ERT) \\
\hline & Platelet $<100,000 / \mathrm{mm}^{3}$ & Consider increasing enzyme dose \\
\hline & Exclude "pseudo-thrombocytopenia" & $\begin{array}{l}\text { Follow ITP guidelines in cases of } \\
\text { immune thrombocytopenia }\end{array}$ \\
\hline & $\begin{array}{l}\text { Bone marrow aspiration and biopsy in } \\
\text { patients with persistent thrombocytopenia }\end{array}$ & $\begin{array}{l}\text { Consider IVIG, rituximab, and } \\
\text { thrombopoietin receptor analogues }\end{array}$ \\
\hline & & $\begin{array}{l}\text { Splenectomy only in life-threatening } \\
\text { thrombocytopenia }\end{array}$ \\
\hline \multirow[t]{2}{*}{ Thrombocytopathy } & $\begin{array}{l}\text { Platelet aggregation tests with: } \\
\text { adenosine-diphosphate, epinephrine, } \\
\text { collagen, ristocetin }\end{array}$ & $\begin{array}{l}\text { Evaluate prior to orthopedic surgery } \\
\text { ERT }\end{array}$ \\
\hline & Platelet adhesion tests & \\
\hline \multirow[t]{5}{*}{ Clotting factors } & Prothrombin time & ERT \\
\hline & Activated partial thromboplastin time & Coagulation factor concentrates for \\
\hline & Mixing tests with normal plasma & postoperative hemorrhage \\
\hline & Coagulation factor level & \\
\hline & von Willebrand factor level & \\
\hline \multirow[t]{3}{*}{ Fibrinolysis } & D-dimer & ERT to decrease coagulation activation \\
\hline & Plasminogen & \\
\hline & Alfa 2-antiplasmin & \\
\hline
\end{tabular}

IVIG, intravenous immunoglobulin.

spleen and moderate baseline thrombocytopenia. ${ }^{25}$ Persistent thrombocytopenia in GD patients treated with ERT for over 4 years relates to refractory splenomegaly. Therefore, life-threatening thrombocytopenia may be one of the few circumstances where splenectomy may still be justified in GD.17,26 The use of rituximab, high-dose gammaglobulin, and thrombopoietin receptor analogues should be considered as therapeutic modalities in Gaucher patients with immune thrombocytopenia.

\section{THROMBOCYTOPATHY}

Hemorrhagic diathesis has been noted in GD patients with platelet counts of more than $100 \times$ $10^{9} / \mathrm{L}$ and normal clotting studies, suggesting platelet function abnormalities. ${ }^{27}$ Platelet functions, namely adhesion and aggregation, were studied in cohorts of GD1 patients, resulting in detection of relatively common function abnormalities in different GD1 patient populations. Mucosal bleeding was reported in GD patients in association with abnormal platelet adhesion; however, the mechanism of reduced platelet adhesion in patients with type GD1 is not clear. ${ }^{16}$ Increased plasma levels of glucocerebroside in patients with GD may affect platelet activation. ${ }^{28,29}$

Reduced platelet aggregation in response to all agonists was observed with a relatively high incidence of unexplained bleeding tendency in these GD1 patients. ${ }^{23,30,31}$ Interestingly, platelet counts and platelet aggregation were shown to improve following ERT. ${ }^{17,30,31}$

\section{CLOTTING FACTOR DEFICIENCIES}

Reduced activity of coagulation factors, namely factors II (FII), V (FV), VII (FVII), IX (FIX), and X (FX), was reported in GD.17,30,32 A high frequency of FXI deficiency was detected among Ashkenazi patients with type $1 \mathrm{GD}$. This may be explained by a relatively common concurrence of both genetic disorders in this population. ${ }^{18,33}$ Hollak et al. reported that the degree of clotting factor deficiencies was highly variable, with coagulation factor levels as low as $15 \%$ in some GD patients. The most frequently encountered clotting factor abnormalities were deficiencies of FV, FX, and FII. ${ }^{17}$ The lowest levels 
were observed in FII, FVII, and FX. Severe deficiencies of FII, FVII, and FX were usually present in the same patients.34,35 Factor V activity was only mildly reduced in some of the patients. Plasma levels of thrombin-antithrombin complexes were found to be elevated in $46 \%$ of the patients, suggesting that the deficiencies in clotting factors were due to consumption caused by enhanced ongoing lowgrade activation of coagulation (especially in patients with splenomegaly) rather than due to impaired synthesis and could be partly restored by ERT. ${ }^{17,27}$

Giona et al. reported that all coagulation factors which were low before ERT returned to normal values after a median time of 28 months (range 663) since the start of ERT. ${ }^{30}$ Hollak et al. ${ }^{17}$ suggested that the effect of ERT on coagulation parameters might be related to the reduction of spleen volume.

\section{ENHANCED FIBRINOLYSIS}

It was also suggested that splenic intravascular coagulation and fibrinolysis might have a role in GD, especially in patients with splenomegaly. Gerrits et al.35 postulated that splenomegaly is associated with chronic consumption coagulopathy. Mitrovic et al. ${ }^{18}$ found correlation between Gaucher cell burden measured by chitotriosidase values and $\mathrm{D}$-dimer, suggesting the relationship between pro-inflammatory cytokines, coagulation activation, fibrinolysis, and natural anticoagulant consumption without overt disseminated intravascular coagulation (DIC).

However, Hollak et al. ${ }^{17}$ reported reduced levels of plasminogen and a2-antiplasmin in 37\% and 20\% of the studied GD1 patients, respectively. The overall fibrinolytic activity, reflected by plasma levels of plasmin-a2-antiplasmin complexes and D-dimer, was enhanced, indicating that the depletion of fibrinolytic proteins is the result of continuing activation of the fibrinolytic system.

\section{CONCLUSION}

Hemorrhagic diathesis is common in Gaucher patients and is caused by various abnormalities of the coagulation pathways, including platelet number and function, coagulation factors, and fibrinolysis. The visceromegaly caused by Gaucher cell infiltration contributes to abnormal production activation and consumption of coagulation factors. Enzyme replacement therapy corrects only part of the coagulopathies in Gaucher disease.

\section{REFERENCES}

1. Grabowski GA. Gaucher disease. Enzymology, genetics, and treatment. Adv Hum Genet 1993; 21:377-441.

2. Pennelli N, Scaravilli F, Zacchello F. The morphogenesis of Gaucher cells investigated by electron microscopy. Blood 1969;34:331-47.

3. Pastores GM. Gaucher's Disease. Pathological features. Baillieres Clin Haematol 1997;10:739-49. Full Text

4. Hughes DA, Pastores GM. Haematological manifestations and complications of Gaucher disease. Curr Opin Hematol 2013;20:41-7. Full Text

5. Horowitz M, Pasmanik-Chor M, Borochowitz Z, et al. Prevalence of glucocerebrosidase mutations in the Israeli Ashkenazi Jewish population. Hum Mutat 1998;12:240-4. Full Text

6. Elstein D, Zimran A. Using the International Gaucher Disease Registry data: can we devise a virtuous circle for treated patients? Am J Hematol 2008;83:887-9. Full Text

7. Elstein D, Zimran A. Review of the safety and efficacy of imiglucerase treatment of Gaucher disease. Biologics 2009;3:407-17.

8. Aviezer D, Brill-Almon E, Shaaltiel Y, et al. A plantderived recombinant human glucocerebrosidase enzyme--a preclinical and phase I investigation. PLoS One 2009;4:e4792. Full Text

9. Grabowski GA, Golembo M, Shaaltiel Y. Taliglucerase alfa: an enzyme replacement therapy using plant cell expression technology. Mol Genet Metab 2014;112:18. Full Text

10. Weinreb NJ, Charrow J, Andersson HC, et al. Effectiveness of enzyme replacement therapy in 1028 patients with type 1 Gaucher disease after 2 to 5 years of treatment: a report from the Gaucher Registry. Am J Med 2002;113:112-19. Full Text

11. Charrow J, Dulisse B, Grabowski GA, Weinreb NJ. The effect of enzyme replacement therapy on bone crisis and bone pain in patients with type 1 Gaucher disease. Clin Genet 2007;71:205-11. Full Text

12. Cox TM, Aerts JM, Andria G, et al. The role of the iminosugar N-butyldeoxynojirimycin (miglustat) in the management of type I (non-neuronopathic) Gaucher disease: a position statement. J Inherit Metab Dis 2003;26:513-26. Full Text

13. Zimran A, Kay A, Gelbart T, et al. Gaucher disease. Clinical, laboratory, radiologic, and genetic features of 53 patients. Medicine (Baltimore) 1992;71:337-53. Full Text 
14. Lesic A, Suvajdzic N, Elezovic I, et al. Iliopsoas haematoma in Gaucher disease. J Inherit Metab Dis 2006;29:593. Full Text

15. Jmoudiak M, Itzchaki M, Hadas-Halpern I, et al. Iliopsoas hematoma in a young patient with type I Gaucher disease. Isr Med Assoc J 2003;5:673-4.

16. Spectre G, Roth B, Ronen G, et al. Platelet adhesion defect in type I Gaucher disease is associated with a risk of mucosal bleeding. $\mathrm{Br} \mathrm{J}$ Haematol 2011;153:372-8. Full Text

17. Hollak CE, Levi M, Berends F, et al. Coagulation abnormalities in type 1 Gaucher disease are due to low-grade activation and can be partly restored by enzyme supplementation therapy. Br J Haematol 1997;96:470-6. Full Text

18. Mitrovic M, Antic D, Elezovic I, et al. Haemostatic abnormalities in treatment-naive patients with Type 1 Gaucher's disease. Platelets 2012;23:143-9. Full Text

19. Flipo RM, Adenis-Lavignasse C, Cortet B, et al. ["Spontaneous" hematoma of the psoas in Gaucher's disease]. Rev Med Interne 1992;13:293-5. [Article in French] Full Text

20. Stein P, Malhotra A, Haims A, et al. Focal splenic lesions in type I Gaucher disease are associated with poor platelet and splenic response to macrophagetargeted enzyme replacement therapy. J Inherit Metab Dis 2010;33:769-74. Full Text

21. Lester TJ, Grabowski GA, Goldblatt J, et al. Immune thrombocytopenia and Gaucher's disease. Am J Med 1984;77:569-71. Full Text

22. Rosenbaum H, Napso $\mathrm{T}$, Bonstein L. Immune thrombocytopenia in type I Gaucher disease. Blood 2007;110:3200a.

23. Givol N, Goldstein G, Peleg O, et al. Thrombocytopenia and bleeding in dental procedures of patients with Gaucher disease. Haemophilia 2012;18:117-21. Full Text

24. Zimran A, Altarescu G, Rudensky B, et al. Survey of hematological aspects of Gaucher disease. Hematology 2005;10:151-6. Full Text

25. Pastores GM, Weinreb NJ, Aerts H, et al. Therapeutic goals in the treatment of Gaucher disease. Semin Hematol 2004;41(4 Suppl 5):4-14. Full Text
26. Cox TM, Aerts JM, Belmatoug N, et al. Management of non-neuronopathic Gaucher disease with special reference to pregnancy, splenectomy, bisphosphonate therapy, use of biomarkers and bone disease monitoring. J Inherit Metab Dis 2008;31:319-36. Full Text

27. Kelsey H, Christopoulos C, Gray AA, Machin SJ. Acquired pseudo-pseudo Bernard-Soulier syndrome complicating Gaucher's disease. J Clin Pathol 1994;47:162-5. Full Text

28. Nilsson O, Hakansson G, Dreborg S, et al. Increased cerebroside concentration in plasma and erythrocytes in Gaucher disease: significant differences between type I and type III. Clin Genet 1982;22:274-9. Full Text

29. Aerts JM, Hollak CE. Plasma and metabolic abnormalities in Gaucher's disease. Baillieres Clin Haematol 1997;10:691-709. Full Text

30. Giona F, Palumbo G, Amendola A, et al. Platelet function and coagulation abnormalities in type 1 Gaucher disease patients: effects of enzyme replacement therapy (ERT). J Thromb Haemost 2006;4: 1831-3. Full Text

31. Gillis S, Hyam E, Abrahamov A, et al. Platelet function abnormalities in Gaucher disease patients. Am J Hematol 1999;61:103-6. Full Text

32. Seligsohn U, Zitman D, Many A, Klibansky C. Coexistence of factor XI (plasma thromboplastin antecedent) deficiency and Gaucher's disease. Isr J Med Sci 1976;12:1448-52.

33. Berrebi A, Malnick SD, Vorst EJ, Stein D. High incidence of factor XI deficiency in Gaucher's disease. Am J Hematol 1992;40:153. Full Text

34. Tavil B, Balci YI, Karacan C, et al. Acquired von Willebrand disease in a Turkish boy with Gaucher disease. Pediatr Hematol Oncol 2007;24:317-19. Full $\underline{\text { Text }}$

35. Gerrits WB, van Aken WG, van der Meer J, Vreeken J. Splenomegaly associated with chronic consumption coagulopathy. Acta Med Scand 1974;195:425-30. Full Text 